\title{
Mizahî Ögelerin Çevirisi Üzerine Bir İnceleme: Bir Noel Gecesi Örneği
}

\section{A Study on Translation of Humorous Elements: An Example of A Christmas Night}

\author{
Gülhanım ÜNSAL 1 (10)
}

${ }^{1}$ Assoc. Prof., Marmara University, Faculty of Arts and Sciences, Department of Translation and Interpreting,

İstanbul, Turkey

ORCID: G.Ü. 0000-0001-7374-3575

Corresponding author:

Gülhanım ÜNSAL,

Marmara Üniversitesi, Fen Edebiyat Fakültesi, Fransızca Mütercim Tercümanlık Anabilim Dalı, İstanbul, Türkiye

E-mail: gulhanim.unsal@marmara.edu.tr

Submitted: 20.03 .2020

Revision Requested: 26.03.2020

Last Revision Received: 21.05.2020

Accepted: 01.07.2020

Citation: Unsal, G. (2020). Mizahî ögelerin çevirisi üzerine bir inceleme: Bir Noel Gecesi örneği. Litera, 30(2), 663-682. https://doi.org/10.26650/LITERA2020-0058 öz

Çeviri, en eski zamanlardan beri, kültürlerarası temel iletişim araçlarından ve kültür çakışmasının önemli biçimlerinden biri olmuştur. Çeviri diller ve kültürlerarası arabulucu niteliğiyle "öteki"nin kültürünü aktarır. Yazın çevirisinde, erek dilde yeniden yaratma sürecinde kültürel ögelerin çevirisi en önemli sorunlardan birini oluşturur. Bu sorun mizah çevirisinde daha da karmaşık bir hal alır. Çünkü her toplum farklı bir mizah anlayışına sahiptir. Bu bakımdan, mizah birçok çeşidiyle yazında çok hassas bir yer tutar. Mizah yazımı ve anlaşııılığını etkileyen ögelerin aynısı çevirisinde de görünür. Bunun için, mizah metinleri ya çevrilemez ya da çevirisi çok zor olarak kabul edilir. Bu nedenle genelde mizah çevirisi kayıp sayılır. Çeviride mizahi kayıpları önleyebilmek çevirmenin hayal gücü, yaratıcılık ve yeniden yazma yeteneğine bağlı kalacaktır. Bu noktadan hareketle, bu çalışmada Guy de Maupassant'ın Nuit de Noël (Bir Noel Gecesi) adlı öyküsü, çevirmen kararları doğrultusunda, devingen eşdeğerlik yaklaşımı bağlamında mizahi ögelerin çevirisi açısından incelenmiş ve çevirisinde uygulanan yöntem ve stratejiler belirlenmiştir. Buna göre, kaynak metinle aynı etkiyi sağlamak amacıyla erek metinde uyarlama yöntemine başvurulduğu; silme, ekleme, değiştirme, sözcüğü sözcüğüne çevirme, ödünçleme, vb. stratejilerin kullanıldığı gözlemlenmiştir. Sonuç olarak, devingen eşdeğerliğin sağlandığı, erek metnin kaynak metinle hemen hemen aynı mizahi etkiyi yarattığı, çevirmenin mizah kaybını en aza indirgediği gözlemlenmiştir.

Anahtar Kelimeler: Mizahi ögeler, mizah türleri, devingen eşdeğerlik, çeviri stratejileri, çevirmen

\section{ABSTRACT}

Translation has been one of the main methods of intercultural communication and an important form of cultural encounters since the earliest times. It transfers the culture of the "other" between languages and cultures as the mediator. In literary translation, the translation of cultural elements is one of the most important problems encountered in the process of rewriting in the target language. This problem becomes even more complicated in the translation of humor as every society has a different sense of humor. In this regard, humor holds a very sensitive place in literature with its many varieties. The same elements that affect writing and intelligibility of humor appear in translation. For this reason, humorous texts are considered as either untranslatable or very difficult to translate. Thus, humor translation is generally 
considered as lost. Being able to prevent losses in humor translation will depend on the imagination, creativity and rewriting ability of the translator. Based on this point, in this study, the humorous story by Guy de Maupassant named Nuit de Noël (A Christmas Night) was selected, and the methods and strategies were applied in the translation were analyzed in the context of functional dynamic equivalence approach in line with the decisions of translator. Accordingly, it is observed that the adaptation method was used in order to provide the same effect as the source text, and some strategies such as addition, omission, substitution, word for word translation and borrowing were used in the target text. As a result, it was observed that dynamic equivalence was achieved, the target text had almost the same humorous effect as the source text and the translator minimized the loss of humor.

Keywords: Humorous elements, types of humor, dynamic equivalence, translation strategies, translator

\section{EXTENDED ABSTRACT}

Translation has been one of the main methods of intercultural communication and an important form of cultural encounters since the earliest times. It transfers the culture of the "other" between languages and cultures as mediator. In literary translation, the translation of cultural elements is one of the most important problems encountered in the process of rewriting in the target language. This problem becomes even more complicated when the translation of humor makes someone laugh shaped by another culture because every culture has a different sense of humor. Humor is a form of amusement and criticism. Humor is the tool to break the automated environment. Humor is universal and it is a serious activity. Humor is based on tolerance between the receiver and the transmitter. There are many types of humorous elements such as physical, linguistic, situational, cultural, etc. Brevity is the most important characteristic of humor. In translation, explaining for better understanding kills humor. The cultural differences emerge as environment, material culture, social culture, religious culture and language culture. Based on this distinction, it can be said that the humor of each society has a close relationship with the lifestyle (material culture) and region. This is why every society has its own humor. People laugh at different topics such as culture, history, geography, society, language, religion, age, education, etc. depending on the people. Humor holds a very sensitive place in literature with its many varieties. Humor texts are format-oriented. For this reason, it can be said that it is included in the narrative text type in Reiss text typology. In this text type, the writer uses the language in an original and creative way. The formal language characteristics such as voice, word, sentence, etc. are important in this type. This type of texts enriches our lives. The same elements that affect writing and intelligibility of humor appear in the translation of this kind of text. For this reason, humorous texts are considered as either untranslatable or very difficult to translate. It can be said that the difficulties of these translations are linguistic, cultural, stylistic and sociolinguistics. Thus, humor translation is generally 
considered as lost. In order for the humor components to have the same effect in the target culture, the target-oriented translation approach should be adopted, the humor translation should be directed towards the target culture and the foreignizing between the receiver and the product belonging to a different culture should be removed. On the other hand, if the humor translation is directed towards the source-oriented, there may be alienation between the product and the receiver. In other words, laughing doesn't happen. And yet, the translator is the person who decides how to represent a foreign culture and what kind of strategy to be followed in translation of the humor. In the translation of humor, the receiver comes before the text. Equivalence can be achieved not by the structure of the original text, but by sticking to the effect it produces. Meaning is translated in the translation of humor. The translator does not destroy the message; s/he changes it for better understanding. Nevertheless, being able to prevent humorous losses in translation will depend on the imagination, creativity and rewriting ability of the translator. Based on this point, in this study, the humorous story by Guy de Maupassant named Nuit de Noël (A Christmas Night) was selected and the humor translation was examined through translator decisions. In this context, the type of humor and the methods and strategies applied in the translation were determined. Accordingly, it was observed that the target-oriented translation approach was adopted in the translation text. It was determined that the adaptation method was used to provide the same effect as the source text. Thus, it provided the dynamic equivalence in the target language. It was identified that among the strategies used were addition, omission, substitution, deletion, word to word translation, borrowing, etc. The translation text was also examined in terms of humor types. The study included five types of humor. These genres can be cited as physical humor, linguistic humor, situational humor, cultural humor and implicit humor. As a result, it was observed that dynamic equivalence was achieved, the target text had almost the same humorous effect as the source text and the translator minimized the loss of humor. 


\section{Giriş}

Anadilin dünya algı ve anlayışını biçimlendirdiği bilinir. Dolayısıyla, her toplum algı ve alımlamasıyla diğerinden ayrılır. Bunun en tipik biçimi toplumların mizah anlayışlarında ortaya çıkar.

Fransızcada ses benzerliğinden (paronymie) dolayı mizaç (l'humeur) sözcüğü ile mizah (l'humour) sözcüğü genellikle karıştırıır. Arapça kökenli mizah, mizacın bir özelliğidir. Hayatın gülünç yönünü vurgulayan bir sanat türü ya da gülmenin sanatlı şekli olarak da bilinen mizahın pek çok tanımından söz edilebilir. Mizah, "gerçeğin gülünç, tuhaf, saçma ve alışılmadık bazı görünüşlerini ortaya çıkaran şaka biçimi”" (Robert, 1987, s. 946); “gülmece” (Türkçe Sözlük, 2005, s.1404); "şaka, latife, eğlence” (Devellioğlu, 2000, s. 655); "toplumsal ya da bireysel kusurları, yetersizlikleri, adaletsizlikleri, vb. doğrudan ve dolaylı olarak eleştiren sanat biçimi; bireye ve topluma yöneltildiği için de bir eleştiri biçimi" (Akkuş, 1998, s. 37); "bir irade ve aynı zamanda, toplum ve insan hayatının etrafımızda bir koruma, bir kefen gibi şekillendirdiği, ölümcül derecede anadile ait, otomatikleşmiş çerçeveyi kırma aracı” (Escarpit, 1994, s. 127); "hayatın çirkinliklerini ve hoş olmayan durumlarını gösteren çok iyi bir araç" (Zeynaligargari ve Alavi, 2011, s. 91); “keskin bir zekânın, sıra dışı, aykııı, ani ve beklenmedik, kimi zaman eğlendirici, kimi zaman sorgulayıcı, kimi zaman da acımasızca yapılarak kazandığı sessiz zafer" (Eker, 2009, s. 54); "olumlu bir eğlence duygusu (duygulanım), bir şeyin komik olduğu kanaati (biliş) ve kahkaha eğilimi (davranış) içeren psikolojik bir tepki" (Bilgin, 2017, s. 10) olarak tanımlanır. Mizah, "kullanımı uzun bir öğrenme gerektiren, doğuştan, yaratma gücü ve anlayış yetisine dayanan bir çeşit büyülü bir süreç olarak kabul edilir" (Laurian, 1989, s. 5). Mizahta "kusurları düzeltme çabası temel amaç olup güldürme esastır" (Karadikme, 2006, s. 46). "Mizah evrenseldir"; "mizah, ciddi bir iştir" diyen Turhan Selçuk (1989, s. 99)'a göre, "mizah yalnız güldürü değildir. Düşündüren, eleştiren, istihza eden, bir çeşit acı duygusu veren, hicveden, karşıt fikirleri kapsayan ve fikirleri beklenmedik, şaşırtıcı bir biçimde sunan türleri vardır. Kara ve pembe mizah deyimleri bu yüzden çıkmışıı" (Çetinkaya, 2006, s. 7; Alay, 2019, s. 24).

Mizah şekilleri "popüler mizah, siyasi mizah ve kara mizah" olarak üç grup altında toplanabilir (Yardımcı, 2010, s. 12). Öngören, mizah çeşitlerinin "latife, şaka, nükte, iğne, taş, hiciv, alay, halt gibi biçimleri olduğunu ve matrak, dalga, gırgır, curcuna gibi mizahi duruşları işaret etmek amacıyla" (1973, s. 31) kullanıldığını belirtir. Mizah ürünü "fıkra, mizahi hikâye, mizahi şiir, karikatür, yazısız karikatür, kukla, komedi, vb. değişik türlerde 
ortaya çıkar" (Öngören, 1973, s. 33). Bu değişik metin türlerine çağına göre yenisi eklenebilir.

Mizahın temelinde eğlence ve hoşgörü vardır (Öngören, 1973, s. 11). Mizahi ögeler "mantık, görüntü ve toplumsal ilişki" bağlamında ortaya çıkar (Öngören, 1973, s. 21-28). Mizah tümcenin mantık yapısıyla bağıntılıdır. Örneğin, "ip" ve "çamaşır" bilindik bir mantıksal bağ kurarken "ip" ve "un" "ipe un sermek" bağı alışılmışın dışında olduğu için mizahi bir anlam taşır. Bunun gibi beklenmedik, alışılmadık, gerçek dışı görüntüler, hareketler, davranışlar kendi başına mizah konusu olabilir. "Hoca'nın eşeğine ters binmesi" buna bir örnek olarak verilebilir. Mizahın mantık ve görüntü yapısı soyutken, ortaya konulan toplumsal ilişki somuttur ve mizah eserinin hikâye dokusunu oluşturur.

Mizah güldürme biçimlerinden biridir ve sadece insan için üretilir. Bu basit ilke bir başarı ölçütüdür. Mizah zekâya hitap eder. Bu nedenle mizahta bir zekâ, bir nükte anlayışına ihtiyaç duyulur. Dalgınlık ve kaygı gülmeye izin vermez. Karikatür gibi bütün biçim bozuklukları gülmeye sebep olur. Gülüncün kaçınılmaz boyutlarından biri dildir ve bu dil ironi, yergi ve şakalarla doludur (Bergson, 1959, s. 9-33; Zeynaligargari \& Alavi, 2011, s. 92).

Sözlü mizah döneminde mizahi hikâyelerin eğlenceli meddah hikâyeleri, fıkralar, masal anlatma teknikleri, mizahi destanlar, vb. birçok geleneği vardır. "Osmanlı İmparatorluğu'nda meddahlar, soytarılar, sultanın çevrelerinde toplanan müşabihler birer güldürü karakteri ve özellikle Ramazan ayında Karagöz gibi gölge tiyatro oyunları birer güldürü unsuru olarak ortaya çıkar" (Gergeon, 2007, s. 84-85).

Meddah oyununun geleneksel Türk tiyatro ve kültüründe önemli bir yere sahip olduğu bilinir. Arapça "medh" sözcüğünden gelen meddah "taklitler yaparak, hoş hikâyeler anlatarak halkı eğlendiren sanatçı" ve mecazî anlamıyla "öven, aşırı övgüde bulunan kimse" anlamına kullanılır (Türkçe Sözlük, 2005, s.1360). Meddahlık, söyleşme, taklit ve canlandırma teknikleriyle dinleyiciyi eğlendirmek amacıyla öykü anlatma sanatı olarak tanımlanabilir. Meddah (kıssahan) bu özellikleriyle tek kişilik tiyatro özelliği gösterir. Meddah oyunu halkın yoğun olarak toplandığı yerlerde sergilenir. Sandalye, değnek ve mendil meddahın kullandığı başlıca eşyalardır. Bu eşyaların her birinin anlatıma aracılık ettiği görülür. Meddah seyirci ile iç içedir ve anlatım biçimiyle, seyredende bir duygudaşlık kurma çabasıyla, Orta Oyunu ve Karagöz'den ayrıldığı görülür. Zira salt güldürüye dayanmaz, bir başka deyişle göstermeci değil, "benzetmeci- 
yanılsamacı" bir tiyatro özelliği taşır (Tekerek, 2001, s. 15). Gerçekçi ve sözlü olan meddah hikâyeleri çok çeşitli konular içerir. Örneğin, meddah hikâyelerinde genelde şapkalı, gözünde cam, yarım yamalak bir Türkçe konuşan Avrupalı konsolosa yönelik hicivler oldukça ilgi görür. Bu türden Avrupalıyı betimleyen unsurlar alay konusu olur ve halk bunlara çok güler (Gergeon, 2007, s. 85). Ancak, "meddah, seçtiği konuya göre seyircide coşkunluk, üzüntü, merak, acıma duyguları yaratır" (Kartal, 2017, s. 13). Her ne kadar oyun süresi hikâyenin uzunluğu ve dinleyicinin ilgisine bağlı olsa da, meddah oyunlarında bir açılış ve kapanış geleneği vardır. Oyunun "Hak dostum, Hak!" sözü, tekerleme ve söz oyunlarıyla başladığı ve"Bu bir kıssa, mecmua kenarında kaydolunmuş, biz de gördük, söyledik. Sakiye sohbet kalmazmış bakî. Her ne kadar sürç-i lisân ettikse affola!" sözleriyle bittiği görülür.

Türk halkının meddah oyunlarıyla eğlendiği dönemlerde Fransızların vodvil oyunlarına güldüğü söylenebilir. Tiyatroda komedinin alt türlerinden biri olan vodvil (vaudeville) sözcük olarak"voix de ville" (şehrin sesi) anlamına gelir ve "Fransız Farsı" olarak da bilinir. Vodvil "hiciv konulu halk türküleri (taşlama), entrika ve yanlış anlama üzerine kurulu hafif komedi anlamına gelir" (Robert, 1987, s. 2067).

Fransa'da 18 yüzyılda öncülüğünü Diderot'un yaptığı orta sınıf tiyatrosu olarak bilinir (Ay, 2012, s. 1). Nivelle de La Chausee'nin, acıklı komedilerinin vodvillerin ilk örneği olduğu söylenebilir. O dönemlerde komedi müzikal ve popüler şarkılara dayanır. Müzikli danslı oyunlarla birlikte, beklenmedik olaylar, yanlış anlaşılmalar, karmaşık aşk ilişkilerini konu alan oyunlar seyircinin ilgisini çeker. 19. yüzyılın sonundan itibaren, genellikle müstehcen, olaylarla dolu bir eylemle betimlenen bir tiyatro türü haline gelir. Vodvilin en çok güldüren mizahi öğesi zina ve kapı çarpmasıdır. Oyun üç temel karakterin -karı, koca ve sevgili- sahnede hızla birbirlerini takip etmeleri ve birbirlerini görmeden buluşmalarıyla gerçekleşir. Vodvilin bir oyun mantığı taşır ve akıldışı abartılar, yinelemeler, şaşırtmalar, rastlantılar oyunun gereği olarak kabul görür. Oyuncular genellikle belli özellikleri öne çıkartılmış kalın çizgili tiplerdir.

Mizah hikâyelerinin varlığını basından; temelini bir yazın türü olan kısa hikâye tekniğinden alır (Öngören, 1973, s. 36-37). Mizahi metinlerin en önemli özelliği kısa olmalarıdır. Çünkü açıklama eklemek mizahı öldürür. Mizahi metinler biçim odaklıdır ve bu yönüyle Reiss'ın anlatımcı ana-metin türü içinde yer aldığı söylenebilir. Göktürk (2010, s. 27)'e göre, "anlatımcı ana-metin türünde yazar dili özgün ve yaratıcı bir şekilde kullanır ve bu türde ses, sözcük, tümce, vb. dilin biçimsel özellikleri önemlidir." Masal, 
roman, çizgi roman, tiyatro, öykü, şiir, şarkı, portre, betimleme, çeşitli olay ve tarih yazıları, vb. metinlerin bu tür içinde yer aldığı ve dünyamızı değiştirip zenginleştirdiği görülür. Mizah, mizahi bir dil, bir çizgi, bir dokunuşla anlatılan her metin türünde bulunabilir ya da başlı başına kendisi bir mizah metni olabilir. Mizah, genelde yazar ile okuyucu, muhatap ile dinleyici arasındaki bağa dayanır.

Yazarın niyeti ve metnin verileri genellikle tarih, siyaset, yazın, bilim, yaşam tarzı, gelenek-görenek, tutum, davranış ve her çeşit alanı içeren yananlam ya da göndergelerinin bütününü kapsar; doğal dil kullanıılarının sürekli olarak maruz kaldığı bu alanlar, coğrafya ve yazının birbiriyle dayanışma içinde olduğu ölçüde, ülkeden ülkeye, dolayısıyla dilden dile değişir (Laurian, 1989, s. 6).

Chartier, "anlatıcı metin türlerinin çevirisinde, yazarın biçemini korumanın ve kaynak dildeki etkiyi erek dilde yaratabilmenin oldukça önemli" $(2012$, s. 68) olduğunu vurgular. Yazara göre, "bu tür metinleri çevirmek çok özel yetiler gerektirir." Bu metin türlerinde "çevirmen hem bir okuyucu, bir çözümleyici, hem dilbilimci, hem de yazardır." Bunun için "çevirmenden sadece içeriği değil, kendi yaratıcılı̆ı̆ını da katarak yazarın biçemini çevirmesi beklenir."

\section{Mizahî Ögelerin Çevirisi}

Çeviri, “hiç itirazsız, kültürel diyalogların (söyleşme) ayrıcalıklı bir alanıdır; bir dili diğerine çevirmek ise birbirine denk iki kültür arasında temas kurmak, birini diğerine açmaktır" (Sélim Abou'dan Akt. Munteanu, 2011, s. 119). Öyleyse, mizah çevirisi kültürel bir çakışmadır. Farklı kültürlerin mizahı her zaman merak uyandırır. Ama ilgisizlik ya da anlaşılmazlığa, hatta yanlış anlaşılmalara maruz kalabilir. Eğer mizahın büyüsü dilsel kullanımdan kaynaklanıyorsa, bir dilden diğerine mizah çevirisi taviz verme gibi görünebilir, ama yine de mümkündür. Mizah çevirisinin zorluğu, mizahın iki -dilsel ve kültürel- özelliğinden gelir. Bu iki etkenin değişebilir oranlarda uyuşması çeviriyi biraz rahatlatır. Mizah sözcüklere gönderim yapan dil ve gerçeğin üzerinden ikili oyundan doğarsa, çeviri üstesinden gelmesi çok zor güçlükler sunar.

Laurian (1989, s. 13)'a göre, mizah yazımı ve anlaşılırlığını etkileyen pek çok unsur vardır. Bu unsurlar şöyle sıralanabilir:

1- sözcüklerin belirli göndergeleri; özellikle bir dilde olup diğerinde bulunmayan dil-dışı göndergeler; 
2- sözcüklerin belirli yananlamları (özellikle bir dilde bir göndergeye bağlı yananlamların diğer dilde denk gelen göndergeye bağlı yananlamların ortak olmayışı durumunda);

3- her dilin eşseslilik, çokanlamlılık, çift anlamlılığı;

4- ses benzerliği algısı;

5- dilsel bir gruba özgü ya da edindirilmiş zihniyet, davranış, psikolojik özellikler;

6- dilsel bir gruba özgü metin türü, biçem türü, reklam türü;

7- bir dilin muhataplarının içine işleyen ahlaki, dini, bilimsel, vb. değerler;

8- dilsel bir grubun (mevcut ya da önceki) sosyal, siyasi, ekonomik çevresi.

Bu unsurlar mizah çevirisinin bilişsel varsayımlarını da özetlemektedir. Bu nedenle, mizahi metinlerin çevirisi alanda bir sorun olarak görülür. Bu tür metinler ya çevrilemez ya da çevirisi çok zor olarak kabul edilir. Çünkü bir kültürde güldürme etkisine sahip olan bir güldürü ögesi diğer kültürde aynı etkiye sahip olmayabilir. Bu bağlamda Nida (2001, s. 111), dilbilimsel, dilsel ve göstergesel olmak üzere üç çeviri yaklaşımı belirler. Dilsel yaklaşımlar arasına koyduğu kültürel boyutta ısrar eder. Nida, çeviri esnasında, bir kültürel dünyadan diğerine geçiş sırasında ortaya çıkan eşdeğerlik ile ilgili soruları Mounin (1963, s. 62)'in görüşlerinden yola çıkarak beş alana ayırır: 1-çevre; 2-maddi kültür; 3-sosyal kültür; 4-din kültürü; 5-dil kültürü. Bu ayrımdan hareketle, her toplumun mizahının yaşam biçimi (maddi kültür) ve bölgesi ile yakın bir ilişkisi olduğu; dolayısıyla mizahi ögelerin çevirisine bağlı güçlülerin sadece dilsel ve kültürel değil, aynı zamanda biçemsel ve sosyodilbilimsel güçlükler olduğu da söylenebilir.

Mizah ögelerinin çevirisinde bu güçlüklerin üstesinden gelebilmek için, Incil çevirisi üzerine yazdığı Toward a Science of Translating (1964) adlı denemesinde Nida (1964, s. 159)'nın, biçimsel eşdeğerlik ve devingen eşdeğerlik olarak ayırdığı iki farklı çeviri yaklaşımına başvurulabilir.

Biçimsel eşdeğerlikte çeviri metin özgün metnin içeriği (tema ve kavramlar) kadar yapı ve biçimini (sözdizimi ve deyimsel ifadeler) de korumalıdır. Devingen eşdeğerlikte ise, çeviri kaynak metin ve alııısı arasında var olan ilişkinin aynısını erek metin ve alıcısı arasında üretmek zorundadır. (Borowczyk, 2009, s. 34)

Biçimsel eşdeğerlikte biçim ve içerik içinde dikkat bizzat iletinin kendisine odaklanır. Ancak, kaynak dil erek dilden ne kadar farklı olursa, erek dildeki sözcükleri değiştirmeden 
ya da yeniden düzenlemeden birebir çeviriyi anlamak çok zor olabilir. Öte yandan, biçimsel eşdeğerlik özgün bilgiyi korumak ve anlamsal incelik farklarını açığa çıkarmak amacıyla çevrilmeden bırakılmış deyim, söz sanatları ve atasözlerini koruyarak özgün metinde ifade edilen anlamın biçimini çözümlemek suretiyle alııının kaynak dile aşina olmasını sağlar.

Devingen eşdeğerlikte, çeviri esas olarak biçim eşdeğerliğinden çok etki eşdeğerliğine yönelir ve ifadenin tamamen "doğal" olması hedeflenir. Raková'ya göre "devingen eşdeğerlikte amaç çeviriyi mümkün olduğu kadar açık ve anlaşılır kılmaktır" (2014, s.106). Her iki dilin alıcısının metnin anlamını aynı şekilde anlaması arzu edilen bir durumdur. Devingen eşdeğerlik ilkesi, çevirinin bir bütün olarak alıcı dile ve kültüre uygunluğuyla biçem seçimi ve düzenleniş açısından iletinin bağlamıyla tutarııı̆ı olarak açıklanabilir. Bir başka deyişle, devingen eşdeğerlik ilkesi, “iletiyi bir dile, kültüre, belli bir tarihsel döneme bağlayan biçimsel kısıtlamalardan mümkün olduğunca kurtarmayı amaçlar. İleti, zaman ve uzamdaki yolculuğunun sonunda dış görünümünde aynı kalamasa da ortaya çıkardığı yanıtla aynı kalabilmelidir" (Bensimon, 1998, s. 7).

Nida, "iki dilin aynı olmadığını, gerek verilen anlamlarda olsun, gerek denk gelen simgelerde ya da simgelerin tümce ve tümceler halinde düzenlenme şekillerinde olsun, diller arasında mutlak bir denkliğin olmadığını, bu nedenle de tam olarak doğru bir çevirinin olmayabileceğini, bir çevirinin etkisi özgün haline yakın olsa da, ayrıntılı bir özdeşliğinin olamayacağını" ifade der. ("Eugene Nida”, 2020)

Bununla beraber, Nida'ya göre, doğru bir çeviri özgün metinle aynı etkiyi üreten bir çeviridir. Bu amaçla üç değerlendirme ölçütü belirler: 1-iletişim sürecinin genel etkililiği; 2-iletinin altında yatan niyetin anlaşılması; 3-hem kaynak hem erek kitlede benzer karşılığın üretilmesi. Ancak bu ölçütler, belli bir çevirinin niteliğini kesin olarak yargılamak söz konusu olduğunda, belirsiz ve kesinlikten uzak kalır (Guidère, 2008, s. 101).

Nida "devingen eşdeğerlik" terimini daha sonra "işlevsel eşdeğerlik" olarak adlandıracaktır. İşlevsel eşdeğerlik, sadece kaynak kültürdeki kaynak metnin işlevi ile erek kültürdeki erek metnin işlevi arasında eşdeğerliğin değil, ama aynı zamanda metnin öncelikli işlevi olarak ortaya çıkacak ve kültürel etkileşim biçimiyle ilişkilendirmek mümkün olacaktır. 
Nida, bir çeviride göz önünde bulundurulması gereken üç etkeni şöyle belirler ("Eugene Nida", 2020):

- iletinin doğası: bazı iletilerde içerik birincil öneme sahip olurken, bazılarında biçimin daha öncelik kazanması.

- yazar ve çevirmenin amacı: biçim ve içerik hakkında bilgi verme; alıcının iletinin sonuçlarını anlayabilmesi için tam anlaşılabilirliği hedefleme; sadece çeviriyi anlamayı hedefleyen kuralcı incelikleri gözetme değil, aynı zamanda çevirinin hiçbir şekilde yanlış anlaşılmasına imkân vermeme.

- kitle türü: gizil kitlenin hem kod çözme yeteneği, hem de gizil ilgi bakımından farklııık göstermesi.

Mizah çevirisinde "çevirmenden kaynak iletiyle kaynak alıcı arasında kurulan ilişkinin aynısını erek iletiyle erek alıc arasında sağlaması beklenir" (Tahir Gürçağlar, 2011, s. 118). Erek dilde doğalığı yakalamak ve erek kültürün bağlamına uygun bir aktarım gerçekleştirmek oldukça önemlidir. Çevirmen metin içi düzeyde yapı sökmek ve kod çözmek için metnin ötesine bakmak zorundadır. Kaynak metnin anlaşıırlığını sağlamalı ve sadece belirli bir bağlamda sözcüklerin ne anlama geldiğini aktarmakla kalmayıp dil, kültür ve değişmeceli özel ögeler arasında düzey değerlendirmesi yapmalıdır. Kaynak metni erek dil dizgesi sınırları dâhilinde etkisini yeniden yaratacak şekilde çevirmelidir. Çevirmenin bütün dil ve dil-dışı bilgisini işin içine katması gerekir. Aksi takdirde, kaynak metnin mizahi etkisi erek metne aktarılamayacak ve mizah çevirisi kayıp sayılacaktır. Çevirmenin"mizahi kayıpları önleyebilmek için kaynak metinde kullanılan mizah türünü iyi kavraması, erek dilin kültürüyle karşılaştırması ve erek dilde aynı değere sahip olup olmadığını, erek alıcının hoşuna gidip gitmeyeceğini araştırması gerekir" (Zeynaligargari ve Alavi, 2011, s. 95). Mizah çevirisinde alıcı metinden daha önde gelir ve devingen eşdeğerlik özgün metnin yapısına değil, ürettiği etkiye sadık kalmayla sağlanabilir. Bunun için, çeviri metnin erek kitlenin mizahı yakalayacağı şekilde mizahi fikri yeniden üretmesi gerekir. Mizahi ögelerin çevirisi, sözcük çevirisinden çok daha ötede, bir anlam çevirisidir. Ancak bu durumda metin ve çeviri eşdeğerdir; çünkü sözcük değil anlam çevrilmiştir. Bu çeviri biçiminde ileti aktarımının çok önemli olduğu, çevirmenin iletiyi yok etmediği, ama onu daha iyi anlaşılması için değiştirdiği söylenebilir.

Mizah metinlerin çevirisi erek dilde alıcı üzerinde aynı etkiyi yaratmıyorsa, bunun metinlerarası ve metinlerüstü olmak üzere iki nedeni olduğu üzerinde durulabilir. Çünkü her toplum kendi mizahını kendisi yaratır ve kültür, tarih, coğrafya, toplum, dil, din, yaş, 
eğitim vb. unsurlara bağıı olarak farklı konulara güler. Bu nedenle çevirmenden erek alıcısını çok iyi tanıyarak kaynak iletiyi erek alıcısına göre uyarlaması, bir başka deyişle erek dilde erek kültür alıcısı için yeniden yazması beklenir.

Vinay ve Darbelnet'in Stylistique comparée du français et de l'anglais adlı eserinde dolaylı stratejiler içinde yer alan uyarlama, "özgün metne gönderim yapan bağlam erek kültürde olmadığı zaman uyarlama yapılır" (1958, s. 52-53) şeklinde betimlenir. Amacın kültürel sözcüklerin uyuşmadığı durumda bir tür durum eşdeğerliği sağlamak olduğu belirtilir. Uyarlama, başka bir dilde tiyatro temsilini amaçlayan dramatik metinleri ve yabancı kültürde ürün ve hizmet tanıtımını amaçlayan reklam metinlerinin çevirisinde kullanılır. Bu metin türleri için Brisset, jeopolitik bir bakış açısı benimser ve "uyarlamayı özgün metnin yeniden bölgeselleştirilmesi olarak betimler" (1986, s. 10). Uyarlama, "yerel bir görünüm vermek için eserin bütün yabancı işaretlerini siler. Kitlenin kendi kültürünün samimi ortamında bulunma yanılsamasına yol açar ve bu yolla eseri üreten ülkenin edebi mirasını artııı” (Brisset, 1986, s. 111). “Her uyarlama özgünlük, eserin ruhuna saygı, özgün tadın korunması adına yapılır, ama aynı zamanda ve belki de genellikle erek kitle adına yapııı" (Delisle, 1986, s. 6). Her durumda, uyarlama çeşitli yeniden yazma yöntemlerine başvurarak aynı işlevi korumaya dayanır (Guidère, 2008, s. 86). Bu uyarlamanın en güncel biçimleri olan silme, ekleme ve ikame işlemleriyle yapılabilir:

- sözcük, tümce ya da paragrafın tamamı gibi özgün metnin bir kısmını çıkarma ya da çevirmemeye dayanan silme işlemi;

- ister metin içinde, ister sayfa altına dip not olarak, ister sözlükçe olarak, özgün metinde olmayan bilgileri açıklama ya da açımlama yoluyla ilave etmeye dayanan ekleme işlemi;

- özgün kültürel bir ögenin yerine eşdeğeri sayılan başka bir öge koymaya dayanan ikame işlemidir.

Nida, çeviride özdeş"eşdeğerler" gibi bir şeyin olmadığını hatırlatarak, bir çevirmenin "en doğal eşdeğerini" bulması ve en az değişiklikle iletiyi iletmesi gerektiğini söyler. Bu değişiklikler erek dilde anlamı "öngörmeye" yarar (Guidère, 2008, s. 60). Bu düşünce ilk defa Nida (1964) tarafından çeviriye uygulanır. Çevirmenin bazı iletileri "telafi etmek" gibi temel görevi vardır. "Telafi" sıra dışı sözcüklerin sırası ya da az kullanılan bir ifadenin varlığı gibi dilsel, bazı kavram, metin türü ya da gündelik hayatta olmayan nesneler gibi kültürel nedenlerle yapılabilir. 
Telafi (compensation), "erek metinde benzer bir etkinin yeniden oluşumuyla, kaynak metindeki etki kaybını örtmeye dayanan bir çeviri yöntemidir" (Guidère, 2008, s. 88). Newmark (1991, s. 144)'a göre, "cinas, ses yinelemesi, tartım, argo, eğretileme ve ad, önad, fiil, belirteç gibi anlam içeren, dünyayı betimleyen sözcükler telafi edilebilir." Hervey ve Higgins (1992, s. 34) telafi yöntemini tür, yer, birleştirme ve ayırma telafisi olarak dörde ayırırlar. Bu telafi türlerinden ilk ikisi (tür ve yer) vazgeçilmez olup aynı metinde bulunabilirken, son ikisi (birleşme ve ayırma) her metnin biçemsel ve her bir dilin sözcüksel özelliklerine göre karşılıklı olarak çıkartılabilir. Hervey ve Higgins (1992, s. 40), tatmin edici bir telafiyi başarmanın zor olduğunu, her şeyin metne ve istenen etkiye bağlı olduğunu ifade ederler.

\section{Amaç ve Yöntem}

Çeviri eğitimine katkı sağlaması planlanan bu çalışmanın amacını, çevirmen kararları doğrultusunda mizahi ögelerin çevirisinde mizah kaybının olup olmadığını araştırmak oluşturmaktadır. Çalışmada, mizahi ögelerin çevirisinde mizah kaybı devingen eşdeğerlik yaklaşımılla en aza indirgenebilir varsayımından hareketle, çeviri metinde devingen eşdeğerliğin sağlanıp sağlanmadığı, çeviri güçlüklerinin neler olduğu ve hangi yöntem ve stratejilerin uygulandığı sorularına yanıt aranmıştır.

Bu çalışmanın amacl, çevirmen kararları doğrultusunda mizahi ögelerin çevirisinde mizahi kaybın olup olmadığını araştırmak, karşılaşılan zorlukları belirlemek ve uygulanan yöntem ve stratejileri açıklamak olduğundan, araştırma yöntemi tarama modelinde betimsel bir nitelik taşımaktadır.

Çalışmada Guy de Maupassant'ın Nuit de Noël adlı mizah öyküsü seçilmiştir. Bir Noel Gecesi olarak dilimize aktarılan metin mizahi ögeler açısından incelenmiştir. Bu bağlamda, mizah tanım ve çeşitlerine yer verilmiş, devingen eşdeğerlik yaklaşımı irdelenmiş, uyarlama ve telafi yöntemleri açıklanmıştı. Seçilen bu öyküden hareketle, mizahi ögeler fiziksel, dilsel, durumsal, kültürel ve örtük olarak beş ana tema altında ele alınmış ve çevirisinde uygulanan yöntem ve stratejiler belirlenmiş ve tablo içinde gösterilmiştir.

\section{Bulgular}

Fiziksel, dilsel, durumsal, kültürel ve örtük olarak beş ana tema altında ele alınan mizahi ögeler ve çevirisinde uygulanan yöntem ve stratejiler şu şekilde gösterilebilir: 


\begin{tabular}{|c|c|c|}
\hline $\begin{array}{l}\text { Yöntem/ } \\
\text { Strateji / } \\
\text { Mizah türü }\end{array}$ & $\begin{array}{c}\text { Kaynak Metin } \\
\text { Nuit de Noël (1982) } \\
\text { Yazar: Guy de Maupassant }\end{array}$ & $\begin{array}{c}\text { Erek Metin } \\
\text { Bir Noel gecesi (sic) (1935) } \\
\text { Çevirmen: Hamdi Varoğlu }\end{array}$ \\
\hline $\begin{array}{l}\text { Uyarlama/ } \\
\text { Ekleme/ } \\
\text { Dilsel } \\
\text { Mizah }\end{array}$ & $\begin{array}{l}\text { "Le Réveillon! le Réveillon! Ah! mais non, je } \\
\text { ne réveillonnerai pas!" }\end{array}$ & $\begin{array}{l}\text { "Noel gecesi ha? Noel gecesi eğlenmek ha? } \\
\text { O, bir defa olur oğlum. Noelde (sic) bir daha } \\
\text { evimden dışarı adım atarsam iki olsun!» }\end{array}$ \\
\hline $\begin{array}{l}\text { Ödünçleme/ } \\
\text { Silme/ } \\
\text { Dilsel Mizah }\end{array}$ & $\begin{array}{l}\text { "Vous vous rappelez comme il faisait froid, } \\
\text { voici deux ans, à cette époque; un froid à } \\
\text { tuer les pauvres dans la rue. La Seine gelait, } \\
\text { les trottoirs glaçaient les pieds à travers les } \\
\text { semelles des bottines; le monde semblait sur } \\
\text { le point de crever." }\end{array}$ & $\begin{array}{l}\text { İki sene önce, Noelde (sic) havanın ne kadar } \\
\text { soğuk olduğunu hatırlarsınız bu tabiî. (...) Sen } \\
\text { nehri (sic) buz tutmuştu. Kaldırımların soğuğu, } \\
\text { köseleden geçip ayaklan donduruyordu. (...) }\end{array}$ \\
\hline $\begin{array}{l}\text { Uyarlama/ } \\
\text { Ekleme/ } \\
\text { Değiştirme/ } \\
\text { Ödünçleme } \\
\text { Dilsel } \\
\text { Mizah }\end{array}$ & $\begin{array}{l}\text { "...vers dix heures, la pensée de la gaieté } \\
\text { courant Paris, le bruit des rues qui me } \\
\text { parvenait malgré tout, les préparatifs de } \\
\text { souper de mes voisins, entendus à travers } \\
\text { les cloisons, m'agitèrent. Je ne savais plus ce } \\
\text { que je faisais; j'écrivais des bêtises; " }\end{array}$ & $\begin{array}{l}\text { Saat ona doğru, sokakların gürültüsü, Parisin } \\
\text { (sic) zevk ve eğlence içinde yüzdüğünü aklıma } \\
\text { getirdi. Bitişik odadan, komşunun supe } \\
\text { hazırlıkları, tabak çatal şıkırtıları işitiliyordu. } \\
\text { Şeytan zihnimi çeldi. Aklım başka yerlerde } \\
\text { dolaşıyordu. Saçmasapan (sic) şeyler yazmağa } \\
\text { başladım. }\end{array}$ \\
\hline $\begin{array}{c}\text { Silme/ } \\
\text { Değiştirme/ }\end{array}$ & $\begin{array}{l}\text { "Je sonnai ma bonne et je lui dis: «Angèle, } \\
\text { allez m'acheter de quoi souper à deux: des } \\
\text { huîtres, un perdreau froid, des écrevisses, } \\
\text { du jambon, des gâteaux. Montez-moi } \\
\text { deux bouteilles de champagne: mettez le } \\
\text { couvert et couchez-vous.» Elle obéit, un peu } \\
\text { surprise. Quand tout fut prêt, j'endossai mon } \\
\text { pardessus, et je sortis." }\end{array}$ & $\begin{array}{l}\text {... hizmetçiyi çağırıp, iki kişilik yiyecek, iki şişe } \\
\text { de şampanya aldırdım. Sofrayı hazırlattım. (...) } \\
\text { Giyindim ve sokağa fırladım. }\end{array}$ \\
\hline $\begin{array}{l}\text { Uyarlama / } \\
\text { Ekleme/ }\end{array}$ & $\begin{array}{l}\text { "Paris est plein de pauvres et belles filles qui } \\
\text { n'ont pas un souper sur la planche, et qui } \\
\text { errent en quête d'un garçon généreux. Je } \\
\text { veux être la Providence de Noël d'une de ces } \\
\text { déshéritées." }\end{array}$ & $\begin{array}{l}\text { Paris sokaklarınıdolduranyoksulkızcağızlardan } \\
\text { birini bulup getiririm. Sofrasında yiyeceği } \\
\text { olmayan nice biçare, güzel kadın vardır ki, } \\
\text { şimdi cömerd (sic) bir erkek arayıp bulmak için } \\
\text { kaldırımlarda gezer dururlar. Bu mübarek Noeî } \\
\text { (sic) gecesi, o zavalılardan birine hızır (sic) gibi } \\
\text { yetişeyim. }\end{array}$ \\
\hline $\begin{array}{l}\text { Silme/ } \\
\text { Uyarlama/ } \\
\text { Sözcüğüu } \\
\text { sözcüğüne/ } \\
\text { Dilsel } \\
\text { Mizah }\end{array}$ & $\begin{array}{l}\text { "J'ai un faible, vous le savez, j'aime les } \\
\text { femmes nourries. Plus elles sont en chair, } \\
\text { plus je les préfère.... } \\
\text { Elle était charmante, toute jeune, brune, } \\
\text { avec de grands yeux noirs." }\end{array}$ & $\begin{array}{l}\text { (...) Şişman kadın hoşuma gider, bilirsiniz. Bir } \\
\text { kadın, ne kadar etli, canlı olursa, bence o kadar } \\
\text { makbuldür... } \\
\text { Genç, esmer güzeli iri gözlü, enfes bir kadındı. }\end{array}$ \\
\hline $\begin{array}{l}\text { Değiştirme/ } \\
\text { Silme/ } \\
\text { Durumsal } \\
\text { Mizah } \\
\end{array}$ & $\begin{array}{l}\text { "Enfin, le moment vint de se mettre au lit, et, } \\
\text { pendant que j'enlevais la table dressée devant } \\
\text { le feu, elle se déshabilla hâtivement et se } \\
\text { glissa sous les couvertures." }\end{array}$ & $\begin{array}{l}\text { Yedik, içtik. (...) Kadın sofradan kalktı ve } \\
\text { alelâcele soyunarak yatağa girdi. }\end{array}$ \\
\hline $\begin{array}{l}\text { Değiştirme/ } \\
\text { Dilsel Mizah }\end{array}$ & $\begin{array}{l}\text { "et je me disais: "J'ai eu rudement raison } \\
\text { d'aller chercher cette belle fille; je n'aurai } \\
\text { jamais pu travailler." }\end{array}$ & $\begin{array}{l}\text { Kendi kendime: «lyi ettim de gittim şu kızcağızı } \\
\text { buldum, diyordum. imkânı (sic) yok bu gece } \\
\text { çalışamıyacağım (sic).» }\end{array}$ \\
\hline
\end{tabular}




\begin{tabular}{|c|c|c|}
\hline $\begin{array}{l}\text { Değiş̧tirme/ } \\
\text { Ekleme }\end{array}$ & $\begin{array}{l}\text { "Un profond gémissement me fit retourner. } \\
\text { Je demandai : «Qu'as-tu, ma chatte ?» Elle ne } \\
\text { répondit pas, mais elle continuait à pousser } \\
\text { des soupirs douloureux, comme si elle eût } \\
\text { souffert horriblement." }\end{array}$ & $\begin{array}{l}\text { Tam bu sırada, yataktan derin bir inilti geldi. } \\
\text { Döndüm. - Nen var kızım, hasta mısın? Diye } \\
\text { sordum. O cevab (sic) vermiyor, dehşetli acılar } \\
\text { içinde kıvranarak inlemekte devam ediyordu. } \\
\text { Derken, birden, müthiş bir feryad (sic) kopardı. }\end{array}$ \\
\hline $\begin{array}{l}\text { Ekleme/ } \\
\text { Durumsal } \\
\text { Mizah }\end{array}$ & $\begin{array}{l}\text { "Tout à coup les voisins se turent, écoutant } \\
\text { ce qui se passait chez moi." }\end{array}$ & $\begin{array}{l}\text { Nihayet komşular sustu. Besbelli bizim odadaki } \\
\text { gürültüyü dinliyorlardı. }\end{array}$ \\
\hline $\begin{array}{c}\text { Uyarlama/ } \\
\text { Dilsel Mizah }\end{array}$ & $\begin{array}{l}\text { "Je répétais: "Où souffres-tu, dis-moi, où } \\
\text { souffres-tu?»" }\end{array}$ & $\begin{array}{l}\text { Cevab (sic) versene acanım? Ne oluyorsun? } \\
\text { Nerenden zorun? diye sıkıştırdım. }\end{array}$ \\
\hline $\begin{array}{l}\text { Silme/ } \\
\text { Değiştirme/ } \\
\text { Durumsal } \\
\text { Mizah }\end{array}$ & $\begin{array}{l}\text { "Elle balbutia: "Oh! mon ventre! mon } \\
\text { ventre!» D'un seul coup je relevai la } \\
\text { couverture, et j'aperçus... Elle accouchait, } \\
\text { mes amis." }\end{array}$ & $\begin{array}{l}\text { Karnım! Ah karnım! diye inledi. Yorganı açtım... } \\
\text { (...) Eyvah! Kadın doğuruyordu. (...) }\end{array}$ \\
\hline $\begin{array}{l}\text { Sözcüğü } \\
\text { sözcüğüne/ } \\
\text { Fiziksel } \\
\text { Mizah }\end{array}$ & $\begin{array}{l}\text { "Alors je perdis la tête; je me précipitai sur } \\
\text { le mur que je heurtai à coups de poing, de } \\
\text { toute ma force, en vociférant: «Au secours, } \\
\text { au secours!»" }\end{array}$ & $\begin{array}{l}\text { Aklım başımdan gidiverdi. Ne yaptığımı bilmez } \\
\text { bir halde duvarı (sic) vurmağa: «Imdad (sic)! } \\
\text { Yetişin!» diye bağırmağa başladım. }\end{array}$ \\
\hline $\begin{array}{l}\text { Silme/ } \\
\text { Değiştirme/ } \\
\text { Ödünçleme/ } \\
\text { Kültürel } \\
\text { Mizah } \\
\end{array}$ & $\begin{array}{l}\text { "Ma porte s'ouvrit; une foule se précipita } \\
\text { chez moi, des hommes en habit, des femmes } \\
\text { décolletées, des Pierrots, des Turcs, des } \\
\text { Mousquetaires." }\end{array}$ & $\begin{array}{l}\text { Iç̧eri, fraklı erkekler, dekolte kadınlar, piyeroler, } \\
\text { piyeretlerden bir kalabalık hücum etti. }\end{array}$ \\
\hline $\begin{array}{l}\text { Değiştirme/ } \\
\text { Ikame/ } \\
\text { Örtük } \\
\text { Mizah }\end{array}$ & $\begin{array}{l}\text { "Eux, ils avaient cru à quelque accident, à un } \\
\text { crime peut-être, et ne comprenait plus. Je dis } \\
\text { enfin : "C'est... c'est... cette... cette femme qui... } \\
\text { qui accouche.»" }\end{array}$ & $\begin{array}{l}\text { Bu manzara karşısında öyle afalladım ki, önce } \\
\text { ne söyliyeceğimi (sic) şaşırdım. Nihayet vaziyeti } \\
\text { anlatabildim. }\end{array}$ \\
\hline $\begin{array}{l}\text { Uyarlama/ } \\
\text { Silme/ } \\
\text { Ekleme }\end{array}$ & $\begin{array}{l}\text { "Alors tout le monde l'examina, dit son avis. } \\
\text { Un capucin surtout prétendait s'y connaître, } \\
\text { et voulait aider la nature. Ils étaient gris } \\
\text { comme des ânes. Je crus qu'ils allaient la tuer ; } \\
\text { et je me précipitai, nu-tête, dans l'escalier, } \\
\text { pour chercher un vieux médecin qui habitait } \\
\text { dans une rue voisine." }\end{array}$ & $\begin{array}{l}\text { Hepsi birden kadının etrafını aldılar. Her } \\
\text { kafadan bir ses çıkıyor, herkes bir akıl } \\
\text { öğretiyordu... Bu bir sürü sarhoş orada } \\
\text { doktorluk taslarken, ben sokağa fırladım. (...) } \\
\text { Karşıki sokakta bir ihtiyar doktor biliyordum. } \\
\text { Onu yatağından kaldırdım, getirdim. }\end{array}$ \\
\hline $\begin{array}{l}\text { Ekleme/ } \\
\text { Durumsal } \\
\text { Mizah }\end{array}$ & $\begin{array}{l}\text { "Quand je revins avec le docteur, toute ma } \\
\text { maison était debout..." }\end{array}$ & $\begin{array}{l}\text { Sokak kapısından girdiğimiz zaman, bütün ve } \\
\text { (sic) halkı ayaklanmıştı.... Ev, düğün evi gibiydi. }\end{array}$ \\
\hline $\begin{array}{r}\text { Dilsel } \\
\text { Mizah }\end{array}$ & $\begin{array}{l}\text { "A ma vue, un cri formidable éclata, et une } \\
\text { laitière me présenta dans une serviette un } \\
\text { affreux petit morceau de chair ridée, plissée, } \\
\text { geignante, miaulant comme un chat; et elle } \\
\text { me dit: "C'est une fille.»" }\end{array}$ & $\begin{array}{l}\text { Ben odadan içeri girince, bir kıyamettir } \\
\text { koptu. Önüme, bir peçeteye sarılmış yumruk } \\
\text { kadar suratını buruştura buruştura kedi gibi } \\
\text { miyavlıyan (sic) bir et yığını getirdiler: } \\
\text { - Kız! Dediler. }\end{array}$ \\
\hline $\begin{array}{l}\text { Sözcüğü } \\
\text { sözcüğüne/ }\end{array}$ & $\begin{array}{l}\text { "Le médecin examina l'accouchée, déclara } \\
\text { douteux son état, l'accident ayant eu lieu } \\
\text { immédiatement après un souper, et il } \\
\text { partit en annonçant qu'il allait m'envoyer } \\
\text { immédiatement une garde-malade et une } \\
\text { nourrice." }\end{array}$ & $\begin{array}{l}\text { Doktor losayî (sic) muayene etti; doğum tok } \\
\text { karnına olduğu için, vaziyetini tehlikeli buldu } \\
\text { ve bir hastabakıcı ile bir sütnine göndereceğini } \\
\text { söyliyerek (sic) çekildi gitti. }\end{array}$ \\
\hline
\end{tabular}




\begin{tabular}{|c|c|c|}
\hline $\begin{array}{l}\text { Uyarlama/ } \\
\text { Silme/ } \\
\text { Fiziksel Mizah }\end{array}$ & $\begin{array}{l}\text { "Je passai la nuit dans un fauteuil, trop } \\
\text { éperdu pour réfléchir aux suites." }\end{array}$ & $\begin{array}{l}\text { O geceyi bir koltukta pinekliyerek (sic) geçirdim. } \\
\text { (...) }\end{array}$ \\
\hline $\begin{array}{l}\text { Dilsel } \\
\text { Mizah }\end{array}$ & $\begin{array}{l}\text { "Il trouva la malade assez mal. /I me dit: } \\
\text { "Votre femme, monsieur..." Je l'interrompis: } \\
\text { "Ce n'est pas ma femme." II reprit: "Votre } \\
\text { maîtresse, peu m'importe.» Et il énuméra les } \\
\text { soins qu'il lui fallait, le régime, les remèdes." }\end{array}$ & $\begin{array}{l}\text { Hastayı bir gün evvelkinden daha fena buldu. } \\
\text { (...) Reçetelerini yazıp tedavi yollarını tarif } \\
\text { ettikten sonra gene çekildi gitti. }\end{array}$ \\
\hline $\begin{array}{l}\text { Ödünçleme/ } \\
\text { Ekleme/ }\end{array}$ & $\begin{array}{l}\text { "Que faire? Envoyer cette malheureuse à } \\
\text { I'hôpital? J'aurais passé pour un manant } \\
\text { dans toute la maison, dans tout le quartier. } \\
\text { Je la gardai. Elle resta dans mon lit six } \\
\text { semaines. L'enfant? Je l'envoyai chez des } \\
\text { paysans de Poissy. II me coûte encore } \\
\text { cinquante francs par mois. Ayant payé dans } \\
\text { le début, me voici forcé de payer jusqu'à ma } \\
\text { mort. Et, plus tard, il me croira son père." }\end{array}$ & $\begin{array}{l}\text { Kadını hastaneye göndermek olamazdı. Bütün } \\
\text { mahalle bana lânet ederdi. Çaresiz evimde } \\
\text { muhafaza ettim. Altı ay yattı. Çocuğu Puassi } \\
\text { köylülerinden bir sütninenin yanına verdim. } \\
\text { Hâlâ ayda elli frank ücretini ben veriyorum. Bir } \\
\text { kere bu işe başlamış bulunduk ve ölünciye (sic) } \\
\text { kadar ödeyeceğiz. Tabiî (sic), sonra da, bana } \\
\text { baba diyecek. İş bu kadarla kalsa gene neyse! }\end{array}$ \\
\hline $\begin{array}{l}\text { Silme/ } \\
\text { Durumsal } \\
\text { Mizah }\end{array}$ & $\begin{array}{l}\text { "Mais, pour comble de malheur, quand } \\
\text { la fille a été guérie... elle m'aimait... elle } \\
\text { m'aimait éperdument, la gueuse! " }\end{array}$ & $\begin{array}{l}\text { Asıl felâketin büyüğü, kadın iyi olduktan sonra, } \\
\text { beni sevmeye başlamaz mı? Hem de çılgınca! } \\
\text { (...) }\end{array}$ \\
\hline $\begin{array}{c}\text { Ekleme/ } \\
\text { Dilsel } \\
\text { Mizah }\end{array}$ & $\begin{array}{l}\text { "- Eh bien? - Eh bien, elle était devenue } \\
\text { maigre comme un chat de gouttières; }\end{array}$ & $\begin{array}{l}\text { Bari bana âşık olduğuna göre o zamanki gibi } \\
\text { güzel kalsaydı! Ne gezer! Sıska, mendebur } \\
\text { birşey (sic) oldu. }\end{array}$ \\
\hline $\begin{array}{l}\text { Değiştirme/ } \\
\text { Silme/ }\end{array}$ & $\begin{array}{l}\text { "et j'ai flanqué dehors cette carcasse qui } \\
\text { me guette dans la rue, se cache pour me } \\
\text { voir passer, m'arrête le soir quand je sors, } \\
\text { pour me baiser la main, m'embête enfin } \\
\text { à me rendre fou. Et voilà pourquoi je ne } \\
\text { réveillonnerai plus jamais." }\end{array}$ & $\begin{array}{l}\text { Başımdan defettim. Fakat kurtulamıyorum. } \\
\text { Hâlâ beni sokak başında bekler, yolumu keser, } \\
\text { elimi, ayağımı öper, canımı sıkar durur. (...) }\end{array}$ \\
\hline
\end{tabular}

Öyküde mizah, etine dolgun, kanlı canlı kadınlardan çok hoşlanan Henri Templier'in, Noel gecesini yalnız geçirmemek için sokaktan esmer, iri gözlü, güzel, etine dolgun bir kadını evine getirmesiyle başlar. Ama kadının dolgun olması, onun fiziksel özelliğinden değil, hamile olmasından ileri gelir. O gece kadın doğum yapar. Öyküde bütün bu beklemedik durum ve olaylar mizahı oluşturur.

Beklenmedik, alışılmadık, gerçek dışı görüntüler, tutumlar, hareketler, davranışların kendi başına mizah konusu olabileceği görüşünden (Bergson, 1959, s. 20) yola çıkarak, öyküde geçen mizah türleri fiziksel, dilsel, durumsal, kültürel ve örtük mizah türü olarak şöyle açıklanabilir:

-Fiziksel mizah: Özellikle karikatür ve çizgi romanlarda bulunduğu gözlemlenir; basit fiziksel şakalar söz konusudur. Türkmen ve Fedakâr (2009, s. 108), mizahta "söz ve hareketin bir bütün halinde yer aldığını; hareketin, sözü desteklediğini ve bazı durumlarda mizahı yarattığını" ifade ederler. "Hareket komiğinin, yinelenen hareketlerden, tipin 
fiziksel ya da karakteristik özelliklerine bağlı olan hareketlerinden, dalgınlık sonucu yapılmaması gereken hareketlerden ve orantısız, abartılı hareketlerden oluştuğunu" vurgularlar. Öyküde fiziksel durumların şaka olmamasıyla beraber, gülmeye sebep olduğu söylenebilir. Fiziksel durumların, hareket ve davranışların, çarpma, vurma, koşuşturma, merdivenleri inme, çıkma, doğum yapma, vb. eylemlerin zihinde bir görüntü oluşturarak fiziksel bir mizah yarattığı söylenebilir.

-Dilsel mizah: Mizahın temel araçlarından biri olan dil iğne, hiciv ve şakalarla doludur (Bergson, 1959, s. 45) ve mizah dilin incelikleriyle sağlanır. Kaynak metinde mizahın en temel aracı olan dilin bütün inceliklerinin kullanıldığı gözlemlenir. Çeviri metnin ise nükte, latife, iğne, vb. mizah çeşitleri ve dili tutulma, kekeleme, konuşamama, ne dediğini bilmeme, aklı başından gitme gibi dilin dille anlatıldığı dilsel inceliklerle dolu olduğu ve böylece mizah kaybının telafi edildiği söylenebilir.

-Durumsal mizah: Yazıda ortaya çıkar ve gerçekdışı, düşsel bir durum yazıyı mizahi kılar (Zeynaligargari ve Alavi, 2011, s. 94). Bergson (1959, s. 45), "aynı anda gerçekleşen ve kesinlikle birbirinden farklı iki olay ve farklı iki anlama sahip olan durumun her zaman gülünç" olduğunu söyler. Dil, gülünç durumları anlatmak ve betimlemek için kullanılır. Durum mizahında güldüren şey, durumu hayal etmek, gözünde canlandırmaktır. Öyküde, Henri Templier'nin Noel gecesi başından geçen gülünç, şaşırtııı, beklenmedik olayların bir tiyatro izler gibi alııının gözleri önüne serildiği söylenebilir.

-Kültürel mizah: Kaynak kültüre ait kültürel ögelerle yapılan mizah çeşidi olduğu söylenebilir. Öyküde geçen, sosyal yaşama ait Noel gecesi kutlama alışkanlığı, Paris'in zevk ve eğlence içinde yüzmesi; sosyal statü göstergesi olarak bir hizmetçiye sahip olma ve bir gecede kız babası olma durumu; gelenek-göreneğe ait yeme içme alışkanlığı, doğum yapan bir kadına yardım etme anlayışı, doktor çağırma, hastabakıcı ve sütnine bulma, evde hastaya bakma durumu; fraklı erkekler, dekolteli kadınlar, piyeroler, piyeretler (palyaço kılıklı insanlar-bu sözcükler Türk ve Müslümanlar yerine kullanılır) gibi giyinme biçimleri vb. kaynak kültüre ait pek çok kültürel ögenin mizahi bir dille anlatımı söz konusudur. Bununla beraber, çevirmenin erek metinde kaynak kültüre ait içeceği -şampanya- kaynak odaklı çeviriye yaklaşarak biçimsel eşdeğerlik yaklaşımı bağlamında çevirirken, Noel menüsündeki yemek adlarını çevirmediği, çıkarmayı tercih ettiği gözlemlenir. Ayrıca, "Ev, düğün evi gibiydi" tümcesiyle, doğum ve düğün kalabalığı arasında bir benzerlik kurarak kaynak ileti ve alıcısı arasında oluşan etkinin aynısını erek ileti ve alıcısı arasında sağlamayı 
amaçladığı ve böylece erek kitlede durumu etkili ve anlaşııır kıldığı ve mizah kaybını telafi ettiği söylenebilir.

-Örtük mizah: Sözcüklerin ardında saklı olan anlamı iyi anlayan belli bir yaş grubu için kullanılan bir mizah türü olarak tanımlanabilir. Kaynak metinde Henri Templier'nin niyeti, sorumluluk alma duygusu ve kadına bakış açısının örtük olarak verildiği gözlemlenir. Sözcüklerin ardına saklanan, açıkça dile getirilmeyen, ancak sezdirilen, satır arasında okunabilen örtük bir mizah yaratılır. Ancak, belli bir birikime, deneyime sahip, belli bir yaş grubu bu mizahı yakalayabilir. Ayrıca, kaynak metnin o dönemin sosyal yaşamına örtük bir mizahi bakış getirdiği ve bu durumun erek kitleye olduğu gibi yansıtıldığı da söylenebilir.

Bulgulardan da anlaşıldığı üzere, çeviri metinde kaynak metinle aynı etkiyi yaratabilmek, mizah kaybını önleyebilmek, olası kayıpları telafi edebilmek için, çevirmenin devingen eşdeğerlik yaklaşımı bağlamında erek odaklı çeviriye yaklaşarak uyarlama yöntemine başvurduğu gözlemlenmiştir. Bunun için yer yer ekleme stratejisi kullanarak genişletme yaptığı, yer yer silme stratejisi kullanarak daraltma yaptığı, daha iyi anlaşılması için ikame stratejisine başvurarak değiştirdiği gözlemlenmiştir. Biçimsel eşdeğerlik yaklaşımı bağlamında kaynak odaklı çeviriye yaklaşarak, kaynak metnin biçimsel özelliklerini koruma aracıyla sözcüğü sözcüğüne çevirdiği, alıcıyı uyarlamanın rahatlığından çekip çıkarmak için yer yer ödünçleme yaptığı gözlemlenmiştir. Dolayısıyla, çevirmenin, "erek alıının en kolay şekilde anlayacağı tarzda dile ya da kültüre has farklı konuların, burada öykünün, içeriğini aktararak" (Köksal, 2005, s. 64) devingen eşdeğerliği sağladığı söylenebilir.

Mizah ögelerinin çevirisinde dikkat çeken şey, her bir mizah türü için ayrı ayrı çeviri stratejinin uygulandığı, bir mizah türüne özgü kesin bir stratejinin olmadığı, dolayısıyla, çevirmenin yaratmak istediği etki ve niyete bağlı olarak farklı çeviri stratejilerini farklı mizah türlerine uyguladığı söylenebilir.

\section{Tartışma ve Sonuç}

Guy de Maupassant'ın Nuit de Noël (Bir Noel Gecesi) adlı öyküsü devingen eşdeğerlik yaklaşımı bağlamında, fiziksel, dilsel, durumsal, kültürel ve örtük olarak beş ana temada ele alınan mizahi ögelerin çevirisi açısından incelenen çalışmanın bulgularına göre; 
- genellikle bir ifade, söz, davranış, tutum, durum, vb. mizahi ögeler ve son tümcelerin gülünç bir etki yarattığı görülmüştür.

- mizah çevirisine bağlı güçlülerin dilsel, kültürel, biçemsel ve sosyodilbilimsel olduğu gözlemlenmiştir.

- mizahi ögelerin çevirisinde mizah kaybının devingen eşdeğerlik yaklaşımıyla en aza indirgendiği gözlemlenmiştir. Bu doğrultuda,

- çevirmenin erek odaklı çeviriye yaklaşarak uyarlama yöntemi ve silme, ekleme, ikame, değiştirme stratejilerine başvurduğu; biçimsel eşdeğerlik bağlamında kaynak odaklı çeviriye yaklaşarak ödünçleme ve sözcüğü sözcüğüne stratejilerini uyguladığı ve böylece mizah kaybını en aza indirgemeye, telafi etmeye çalıştığı;

- çevirmenin yazar ve kaynak metnin etkisinin erek kitlenin mizahı yakalayabileceği şekilde mizahi fikri yeniden oluşturduğu; mizahi ögelerin çevirisinde iletiden çok alıcının ön planda olduğunu ve mizahi iletiyi erek kitlenin yaş, eğitim, cinsiyet, ruhsal durumu, vb. ölçütleri, ihtiyaç ve beklentilerini göz önünde bulundurduğu;

- çevirmenin erek kitle için somut ve eğlenceli olacak şekilde, kaynak metinle aynı mizahi imgeyi üretebilecek sözcük, tümce ve dilbilgisel yapılarını seçtiği; ancak, yerel rengin bölgesel izini taşıyan terimleri erek dile çevirmek söz konusu olduğunda, her iletişim biçiminde her zaman bir kayıp ya da bozulma olduğunu bilmek gerektiği;

- çeviri ve kültür arasında çok sıkı bir bağ olduğu; her ülkenin mizah dilini anlamak için o ülkenin kültürünü bilmek gerektiği; zira özgün metnin yerel rengini ve kültürünü korumanın sadakat eksenlerinden biri olduğu söylenebilir.

- çevirmenin mizahi etkiyi erek dile doğru ve etkili bir şekilde aktarabilmesi için, doğuştan bir mizah anlayışına, belli bir yaratııılığa ve büyük bir hayal gücüne sahip olması gerektiği kanaatindeyiz. Ayrıca, çevirmenin çabası, hayal gücü, yeteneği, ustalığı ve yaratıcılığıyla mizahın çevrilemezlik anlayışııın aşılacağı düşüncesindeyiz. - yabancı dil öğretiminde, mizahi metinlere yer vermek ve ikinci dilin mizahını anlaşıı kılmak önerilebilir. Temel düzey öğrencileri için, günün şakası belirlenebilir. Bu öğrencilere hem hızlı bir öğrenme hem de farkındalık kazandıracaktır. Orta düzey öğrencileri için, ünlü yazarların mizahi metinlerden çeviriler yapılabilir. Bu öğrencileri hem diğerinin mizah anlayışını kabul etmeye götürecek, hem de eğlenerek öğrendikleri için mizah çevirisinin zorluklarını üstesinden gelebilecek yeterliliğe eriştirecektir. Sözlü çalışmak yazılı çalışmaktan çok daha zor olsa da, ileri düzey öğrencileri için, radyo yayınları, tiyatro oyunları, romanlar, basın, vb. mizahi metinler seçilebilir. Sonuç olarak, mizahi metinlere yabancı dil öğretiminin her düzeyinde yer verilmesinin çeviri eğitimini destekleyeceği, yazılı ve sözlü çeviri eğitimine çok büyük katkılar sağlayacağı düşüncesindeyiz. 


\section{Hakem Değerlendirmesi: Dış bağımsız.}

Çıkar Çatışması: Yazar çıkar çatışması bildirmemiştir.

Finansal Destek: Yazar bu çalışma için finansal destek almadığını beyan etmiştir.

Peer-review: Externally peer-reviewed.

Conflict of Interest: The author has no conflict of interest to declare.

Grant Support: The author declared that this study has received no financial support.

\section{Kaynakça}

Alay, O. (2019). Mizah kavramı ve mizahın tarihsel süreci. Eleştiri/Inceleme, Türk Dili, Dil ve Edebiyat Dergisi, CXVI (808), 22-30. http://tdk.gov.tr/wp-content/uploads/2019/05/5_Okan-Alay (10.02.2020).

Akkuş, M. (1998). Nef'i ve siham-ı kaza. Ankara: Akçağ Yayınları.

Ay, C. (2012). Vodvil. Tiyatro türleri. http://www.etiyatro.net/index.php/tr/genel-bilgiler/tiyatro-turleri/tiyatroturleri-vodvil. (24.07.2020).

Bensimon, P. (1998). Presentation. Palimpsestes, XI, Traduire la culture. Paris: Presses de la Sorbonne Nouvelle.

Bergson, H. (1959). Le rire, essai sur la signification du comique. Paris, PUF. http://classiques.uqac.ca/classiques/ bergson_henri/le_rire/Bergson_le_rire.pdf (08.03.2020).

Bilgin, B. (2017). Pazarlamada mizah. Koç Üniversitesi Fener Dergisi, 11, 10-15.

Brisset, A. (1990). Sociocritique de la traduction: Théatre et altérité au Québec (1968-1988). Montréal: Le Préambule. Borowczyk, P. (2009). De l'équivalence à l'adaptation. Studia Romanica Posnaniensia, 36, 33-54.

Chartier, D. (2012). Traduction -histoire, théories, pratiques-. Toulouse: Presses Universitaires du Mirail.

Çetinkaya, G. (2006). Gırgır dergisinin Türk Halkbilimi açııından incelenmesi. (Yüksek Lisans Tezi). Hacettepe Üniversitesi Sosyal Bilimler Enstitüsü, Ankara.

Delisle, J. (1986). Dans la coulisses de l'adaptation théatrale. in Circuit, 12, 3-8.

Devellioğlu, F. (2006). Osmanlıca-Türkçe ansiklopedik lügat. Ankara: Aydın Kitapevi.

Eker, G. Ö. (2009). Insan, kültür, mizah (eğlence endüstrisinde tüketim nesnesi olarak mizah). Ankara: Grafiker Yayınları.

Eugene Nida. (2020, 30 Nisan). Vikipédia içinde. https://fr.qwe.wiki/wiki/Eugene_Nida\#tTheories.

Gergeon F. (2007). Osmanlı Imparatorluğu'nda gülmek. Doğu'da Mizah içinde. (Çev.: A. Berktay). İstanbul: YKY Yayınları.

Göktürk, A. (2010). Çeviri: Dillerin dili. İstanbul: YKY Yayınları.

Guidère, M. (2008). Introduction à la traductologie. Bruxelles: De Boeck.

Hervey, S., Higgins, I. (1992). Thinking translation. A course in translation method: French to English, London, NewYork: Routledge.

Karadikme, A. (2006). "Ironi" kavramı ve Ahmet Hamdi Tanpınar'n eserlerinde ironi. (Yüksek Lisans Tezi). Cumhuriyet Üniversitesi Sosyal Bilimler Enstitüsü, Sivas. 
Kartal, A. (2017). Meddahlık geleneğinin günümüz sanatçılarındaki yansıması üzerine bir değerlendirme. Turkish Academic Research Rewiev, 2(2), 11-20.

Köksal, D. (2005). Çeviri eğitimi: Kuram ve uygulama. Ankara: Nobel Yayınları.

Laurian, A. M. (1989). Humour et traduction au contact des cultures. in Humour et traduction, Meta Journal des traducteurs, 34(1), 5-14. https://id.erudit.org/iderudit/003418ar/ (05.10.2019)

Maupassant, G. de (1882). Nuit de noël. dans Gil Blas. maupassant@free.fr (13.02.2020).

Maupassant, G. de (1935). Bir noel gecesi. (Çev. : H. Varoğlu). Cumhuriyet -26.10.1935-4 pdf.

Mounin, G. (1963). Les problèmes théoriques de la traduction. Paris: Gallimard.

Munteanu, P. (2011). Traduction et culture. http://www.diacronia.ro/ro/indexing/details/A5148/pdf. (10.05.2020)

Newmark, P. (1991). About translation. Clevedon: Multilingual Matters.

Nida, E. A. (2001). Contexts in translating. Amsterdam \& Philadelphia: John Benjamins.

Nida, E. A. (1964). Toward a science of translating. Leiden: Brill. https://tr.scribd.com/doc/294853332/EugeneNida-Toward-a-science-of translating-bible translating - 1964-pdf (02.05.2020).

Öngören, F. (1973). 50 yılın Türk mizah ve karikatürü. (2. bs). İstanbul: İş Bankası Yayınları.

Raková, Z. (2014). Les théories de la traduction, Brno: Masarykova Univerzita.

Robert, P. (1987). Le Petit Robert 1: dictionnaire alphabétique et analogique de la langue française. Paris: Hachette.

Selçuk, T. (1989). Grafik mizahın büyük ustası Turhan Selçuk. Haz. Alpay Kabacalı. İstanbul: Turhan Yayınevi.

Tahir Gürçağlar, Ş. (2011). Çevirinin $A B C^{\prime}$ si. İstanbul: Say Yayınları.

Tekerek, N. (2001). Popüler halk tiyatrosu geleneğimizden çağdaş oyunlarımıza yansımalar. Ankara: Kültür Bakanlığı Yayınları.

Türkçe Sözlük (2005). (10. bs). Ankara: TKD Yayınları.

Türkmen, F., Fedakâr P. (2009). Türk halk tiyatrosunda hareket komiğine bağlı mizahi unsurlar. Millî Folklor Dergisi, 21(82), 98-109.

Vinay, J. P. \& Darbelnet, J. (1958), Stylistique comparée du français et de l'anglais. Paris: Didier. Yardımcı, İ. (2010). Mizah kavramı ve sanattaki yeri. Uşak Üniversitesi Sosyal Bilimler Dergisi, 3(2), 1-41.

Zeynaligargari, S. \& Alavi, F. (2011). L'art de la traduction de I'humour dans la littérature pour enfants: la traduction du Petit Nicolas en persan. Traduire, 224, 90-108. 